\title{
SUMO-1 Gene Silencing Inhibits Proliferation and Promotes Apoptosis of Human Gastric Cancer SGC-7901 Cells
}

\author{
Lifang Jin ${ }^{a}$ Kexin Shen ${ }^{b}$ Tong Chen ${ }^{b}$ Huaiyu Zhang ${ }^{b}$ Wei Yu \\ ${ }^{\mathrm{a}}$ Department of Hematology and Oncology, the Second Hospital of Jilin University, ${ }^{\mathrm{b}}$ Department \\ of Gastrointestinal Colorectal and Anal Surgery, China-Japan Union Hospital of Jilin University, \\ Changchun, China
}

\section{Key Words}

Gastric cancer - SUMO-1 - Gene silencing - shRNA - Cell proliferation - Cell cycle • Cell apoptosis

\begin{abstract}
Background: It has been reported that blocking small ubiquitin-like modifier (SUMO) conjugation by silencing SUMO gene remarkably decreased tumor growth in vivo. However, few studies have examined the relationship between SUMO gene silencing and gastric cancer (GC). The study aims to explore the effects of SUMO-1 gene silencing on GC cell proliferation and apoptosis. Methods: GC cells were cultured and divided into 5 groups: the blank group (without any transfection or treatment), the empty vector group (transfected with empty vector), the shRNA-SUMO-1-1 group (transfected with shRNA-SUMO-1-1 plasmid), the shRNASUMO-1-2 group (transfected with shRNA-SUMO-1-2 plasmid), and the shRNA-SUMO-1-3 group (transfected with shRNA-SUMO-1-3 plasmid). Cell Counting Kit-8 (CCK-8) assay was performed to examine cell proliferation. Annexin V/PI staining combined with flow cytometry were used to detect cell apoptosis. Quantitative real-time polymerase chain reaction (qRT$\mathrm{PCR}$ ) and Western blotting were employed to measure the mRNA and protein expressions of SUMO-1, P53, Bcl-2 and c-myc, respectively. Results: SUMO-1 mRNA and protein expressions were decreased after transfecting with shRNA-SUMO-1. Compared with the blank group, the shRNA-SUMO-1-1 group presented a remarkable decreased proliferation of SGC-7901 cells. Significant increase in cell apoptosis rate was observed. Bcl-2, c-myc and P53 expressions were declined after transfecting with shRNA-SUMO plasmid. Conclusion: Our study provided evidence that SUMO-1 gene silencing could decrease proliferation and promote apoptosis in GC cells.

(C) 2017 The Author(s)
\end{abstract}

Published by S. Karger AG, Basel

\section{Introduction}

According to the data released by the International Agency for Research on Cancer, gastric cancer (GC) ranks the fourth most frequently occurring cancer worldwide after lung, 
breast and colorectal cancers and also accounts for the second most common cancer-related cause of death after lung cancer [1]. With a geographical variation in incidence of the cancer, its mortality in China tends to increase with a 5-year survival rate at only $30 \sim 40 \%$ and a poorer prognosis for advanced tumors, which severely pose a threat to the health and life of people [2, 3]. It has been suggested that approximately $66 \sim 75 \%$ of GC risk could be reduced with high intake of fruit and vegetables and low consumption of salted foods [4]. Currently, GC relies on surgery combined with chemotherapy and adjuvant chemoradiotherapy for its clinical treatment, which is somewhat effective in prolonging patients' overall survival and relapse-free survival but failed to inhibit GC recurrence and metastasis [5, 6]. Furthermore, in spite of the advances in early diagnosis and treatment modalities, the side effects of chemotherapy and frequent recurrence remain tricky problems in its treatment, thus fueling a great need for identification of new and effective anti-cancer agents for reducing the mortality [7]. It has been revealed that certain genes such as vitamin E succinate (VES) can block cell cycle, arrest DNA synthesis and induce apoptosis in human GC SGC-7901 cells, therefore inhibiting cell growth [8]. The mechanism of the apoptosis of SGC-7901 cells, however, still remains unclear [9].

Small ubiquitin-like modifier (SUMO) is known as a group of proteins which conjugate to lysine residues of target proteins, and further modifying their activity, stability, and subcellular localization, a large number of whose substrates are transcription factors or other nuclear proteins involved in gene expression $[10,11]$. SUMO conjugation, or SUMOylation, plays crucial roles in chromosomal organization and function, genome stability, quality control of newly synthesized proteins, proteasomal degradation of proteins and DNA damage repair, which makes obvious increase in levels of SUMO-conjugated proteins likely to exert a major impact on the fate of cells $[12,13]$. Sumoylation is known to affect cellular processes in a wide range of diseases, including human astrocytic brain tumors, glioblastoma and breast cancer $[12,14]$. It is reported that blocking SUMO conjugation by silencing SUMO expression remarkably modifies gene expression and reduces cancer tumorigenesis, making silencing SUMO a promising method to treat cancers [15]. However, few studies have been reported so far to inquire into the relationship between SUMO gene silencing and GC. Thus, the present study initiated to probe into what an effect SUMO-1, one isoform of SUMO family, has on the proliferation and apoptosis of SGC-7901 cells in GC.

\section{Materials and Methods}

Ethics statement

The study was approved by clinical experiment ethical committee of China-Japan Union Hospital of Jilin University and informed consents were obtained from all study subjects.

\section{Specimens collection}

Specimens were extracted from GC tissues and adjacent normal tissues ( $5 \mathrm{~cm}$ beyond cancer lesions) of 35 GC patients who were diagnosed by pathological examination in GC surgical department of China-Japan Union Hospital of Jilin University. These 35 patients included 23 male and 12 female patients, and they were 28 years old to 82 years old with an average age of $55.89 \pm 15.12$ years old. The inclusion criteria of patients were: complete medical records, no other elementary diseases or chronic diseases or combined other body malignant tumor. And patients with incomplete medical records, or had radiotherapy or chemotherapy before operation were excluded. Specimens were washed by normal saline many times, and then connective tissues and necrotic tissues were cut off. Two or three pieces of $0.5 \times 0.5 \times 0.3 \mathrm{~cm}^{3} \mathrm{GC}$ tissues were extracted. All specimens were disintegrated by lysis solution (7 mol/Lurea, $2 \mathrm{~mol} / \mathrm{L}$ thiourea and 4\% CHAPS), added with proteinase inhibitor (Cocktail), after that, supernatant extracted by centrifugation was quantitated by butyleyanoacrylate (BCA) method, and stored at $-80^{\circ} \mathrm{C}$.

Immunohistochemistry (IHC)

GC tissues were immobilized by $40 \mathrm{~g} / \mathrm{L}$ formaldehyde at once separated, then paraffin-embedded, and finally were cut into slices. After that, they were routinely dewaxed and hydrated. A total of 0.01 mol/L citrate buffer were applied for antigen retrieval at high temperature and high pressure. The horse 


\section{Cellular Physiology Cell Physiol Biochem 2017;41:987-998 \begin{tabular}{l|l|l|l}
\hline DOI: 10.1159/000460836 & (c) 2017 The Author(s). Published by S. Karger AG, Basel \\
www.karger.com/cpb
\end{tabular} \\ Jin et al.: Effects of SUMO-1 Gene Silencing on Gastric Cancer}

serum sealing fluid was dropwise added into specimens and extra fluid was throwing away after 20 min conservation at indoor temperature. The specimens were added with $50 \mu \mathrm{L}$ SUMO-1 (ab32058, 1: 500 attenuation, Abcam company) as primary antibody, and stored one night at $4^{\circ} \mathrm{C}$. Then they were reheated for $45 \mathrm{~min}$ at $37^{\circ} \mathrm{C}$, washed by phosphate buffer saline (PBS) 3 times with 5 min each time. A total of $40 \sim 50$ $\mu \mathrm{L}$ second antibody were added into them, and stored for $1 \mathrm{~h}$ at $37^{\circ} \mathrm{C}$. Then they were washed by PBS 3 times with 5 min each time. The coloration was made by 3,3'-diaminobenzidine (DAB) for $5 \sim 10 \mathrm{~min}$, and then they were washed by PBS for $10 \mathrm{~min}$. Specimens were counterstained by hematoxylin for $2 \mathrm{~min}$, and then experienced dehydration, transparent disposal, sealing sheet and microscopy. Under optical microscope, positive expression was indicated by uneven thickness of dyed cell nucleus with color of yellowish to claybank. As a negative control, PBS was used instead of the primary antibody.

\section{Cell culture}

GC primary cells were collected by digesting GC tissues with collagenase digestion method, and then to be observed after trypan blue staining. Primary cells were purified and sub-cultured to be stable continuous cell lines. Their cellular morphology was observed under optical microscope before and after hematoxylineosin (HE) staining when they were immobilized by $95 \%$ ethyl alcohol. Purification: after the fusion degree of primary cells which grew with adherence came to be $80 \%, 0.25 \%$ trypsin were applied to digest the specimens; when cancer cells turned round and floated under microscope and fibroblasts started to fall off, $2 \mathrm{~mL}$ 10\% FBS were added to stop digestion; then falling fibroblasts and cancer cells with low activity were removed; specimens culture continued till fibroblasts adhered to wall while cancer cells did not adhere to wall, where these cancer cells were cultured in a new culture plate. Subculture: purified cancer cells were inoculated to 24-well plate; when fusion degree came to be $80 \% \sim 90 \%$ area of whole culture dish, specimens were digested by pancreatin, and were inoculated to 12 -well plate, 6 -well plate and $10 \mathrm{~cm}$ plate in turn; when fusion degree came to be $80 \%$ of $10 \mathrm{~cm}$ plate, they were digested and sub-cultured. The specimens were cultured and sub-cultured by RPMI-1640 medium (HyClone company) which contained $10 \%$ fetal calf serum (FCS) (Gibco Company, USA), at $37^{\circ} \mathrm{C}$ and $5 \% \mathrm{CO}_{2}$ constant temperature incubator.

\section{Model construction}

The pSilencerTM 3.1-H1 neo plasmid was used to build RNA interference (RNAi) system that was effective to interfere SUMO-1. In accordance with mRNA sequence of SUMO-1 (NM003352), following the classic siRNA design principles, the siRNA software with online program of Promega company was applied to seek target sequence complied with design feature, from the downstream of SUMO-1 initiation codon. The basic local alignment search tool (BLAST) Search was made to confirm that these target sequence had no homology with the known sequences. BamH 1 and Hind III were selected as restriction sites. The target sequences sites and their base sequences showed as Table 1. According to the base sequences of SUMO1 target sequences in Table 1, the oligonucleotide template expressing shRNA was transferred by online program of Ambion company, and synthesized by Shanghai Sangon Biological Engineering Technology \& Service Co., Ltd. The synthesized oligonucleotide were mixed according to equal molar ratio, and then they were added into annealing buffer and slowly annealed to indoor temperature after heated in $95^{\circ} \mathrm{C}$ water bath for $5 \mathrm{~min}$. The pSilencer ${ }^{\mathrm{TM}}$ 3.1-H1 neo plasmid was linearized by dual-enzyme digestion of BamH 1 and Hind III, and next it was fixed with three annealing and linked template DNAs in the above table overnight. The pSilencerTM 3.1-H1 neo plasmid was connected with oligonucleotide inserted in three target sequences of SUMO-1 in Table 1, of which recombinant plasmids were separately named as shRNA-SUMO-1-1, shRNASUMO 1-2, and shRNA-SUMO 1-3. These plasmids were processed overnight and stored at $-20^{\circ} \mathrm{C}$. These three plasmids had restriction enzyme digestion by BamH 1 and Hind III, of which enzyme-digested products were analyzed and identified by agarose gel electrophoresis.

Table 1. SUMO-1 target sequence sites and their base sequences. Note: SUMO-1, small ubiquitin-like modifier-1

\begin{tabular}{lc}
\hline Target sequence sites & Base sequences \\
\hline $001(267-285)$ & 5'-TGACAACACATCTCAAGAA-3' \\
$002(309-327)$ & 5'-GACAGGGTGTTCCAATGAA-3' \\
$003(342-361)$ & 5'-TCTTTGAGGGTCAGAGAAT-3' \\
\hline
\end{tabular}




\section{Cellular Physiology Cell Physiol Biochem 2017;41:987-998

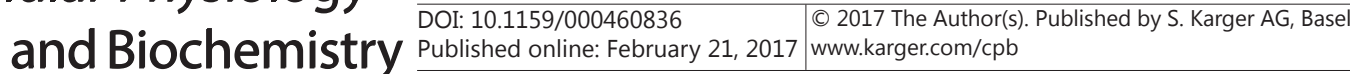

Jin et al.: Effects of SUMO-1 Gene Silencing on Gastric Cancer

\section{Cell transfection}

The cells were transfected by Lipofectamine2000 liposome transfection reagent kit of Invitrogen company. One day before transfection, $0.25 \%$ pancreatin were used to digest cells and count as well. And then these cells were added into 6-well plate of RPMI 1640 complete medium with $5 \times 10^{5}$ cells/well. These plasmids were respectively attenuated by $100 \mu \mathrm{L}$ serum-free RPMI 1640 medium. And a total of $40 \mu \mathrm{L}$ Lipofectamine2000 were attenuated by $1000 \mu \mathrm{L}$ serum-free RPMI 1640 medium. These attenuated plasmids and Lipofectamine2000 solution were mixed together in $10 \mathrm{~min}$, and then stored at indoor temperature for $20 \mathrm{~min}$. A total of $250 \mu \mathrm{L}$ were extracted and added into 6-well plate, blending lightly. The subjects were divided into 5 groups, including the blank group (without any transfection or treatment), the empty vector group (transfected with empty vector), the shRNA-SUM0-1-1 group (transfected with shRNASUM0-1-1 plasmid), the shRNA-SUMO-1-2 group (transfected with shRNA-SUMO-1-2 plasmid), the shRNASUM0-1-3 group (transfected with shRNA-SUMO-1-3 plasmid). After transfection, they were cultured for $6 \mathrm{~h}$ at $37^{\circ} \mathrm{C}$ and $5 \% \mathrm{CO}_{2}$, and finally continued to culture after changing media with serum RPMI-1640 complete medium.

\section{Cell counting kit-8 (CCK-8)}

GC SGC-7901 cells in logarithmic phase were extracted and digested by $0.25 \%$ pancreatin, and to be counted in its single-cell suspension. Then $1 \times 10^{4}$ cells $/ \mathrm{mL}$ cell suspension was prepared, where cells were inoculated into 96-well plate by $150 \mu \mathrm{L}$ and 1500 cells per well, 3 complex holes per group. When fusion degree of cells in each group came to $80 \%$, the complete medium was removed, and cells were continued to be cultured for $4 \sim 6 \mathrm{~h}$ with serum-free medium, which synchronized cell cycle of all groups. Cell plate were taken out at $0 \mathrm{~h}, 24 \mathrm{~h}, 48 \mathrm{~h}$ and $72 \mathrm{~h}$ respectively and then continue to be cultured for $2 \mathrm{~h}$ after $10 \mu \mathrm{L}$ CCK-8 (making no bubble, otherwise influence optical density (OD) value reading) were added into them. The OD value were read at the location of $450 \mathrm{~nm}$ on microplate reader, and cell growth control rates were calculated by the following formula: control rate $(\%)=($ A value of control well - A value of experimental well)/A value of control well $\times 100 \%$. Each experiment repeated five times.

\section{Flow cytometry}

Cell cycle of cells each group were detected by propidium iodide (PI) staining and flow cytometry. SGC-7901 cells of each group were separately inoculated into five $10 \mathrm{~cm}$ cell culture plates by $1 \times 10^{6}$ cell/ plate. They were cultured for $24 \mathrm{~h}$ at $37^{\circ} \mathrm{C} 5 \% \mathrm{CO}_{2}$ incubator. After that, cells were collected and washed twice with pre-cooled PBS. Then they were immobilized by $75 \%$ frozen ethyl alcohol at $-20^{\circ} \mathrm{C}$, followed by which they were washed with pre-cooled PBS. The next stage was that cells were re-suspended by 200 500 $\mu \mathrm{L}$ pre-cooled PBS, $30 \mathrm{~min}$ in $37^{\circ} \mathrm{C}$ water bath after added with $20 \mu \mathrm{L}$ Rnase A solution. And then 400 -mesh sieve were used to filter cells, followed by incubated for $30 \mathrm{~min}$ to $1 \mathrm{~h}$ at $4^{\circ} \mathrm{C}$ away from light after blending with $400 \mu \mathrm{L}$ PI. Finally, specimens were filtered by yellow nylon mesh. Cell cycle of cells in each group was detected by Becton Dickinson flow cytometer (BD, USA) (cells collection and washing should avoid mechanical damage which might cause loss of cells DNA to influence the results accuracy).

Cell apoptosis detection used Annexin V/PI double-staining. SGC-7901 cells of each group were separately inoculated into five $10 \mathrm{~cm}$ cell culture plates by $1 \times 10^{6}$ cell/plate. They were cultured for $24 \mathrm{~h}$ at $37^{\circ} \mathrm{C} 5 \% \mathrm{CO}_{2}$ incubator. After that, cells were collected and prepared into single-cell suspension. Then cells were blending with $500 \mu \mathrm{L}$ Annexin V Binding Buffer, $5 \mu \mathrm{L}$ Annexin V-FITC and $5 \mu \mathrm{L}$ Propidium Iodide in order, $10 \mathrm{~min}$ at indoor temperature away from light. Finally, specimens were filtered by yellow nylon mesh. Cell apoptosis also were detected by BD flow cytometer (BD, USA).

\section{Quantitative real-time polymerase chain reaction ( $q R T-P C R$ )}

Total RNA of cells in each group were extracted by Trizol, while reverse transcription was processed by invitrogen kit, and at last PCR amplified reaction were conducted. The first stage was pre-denaturation at $94^{\circ} \mathrm{C}$ for $5 \mathrm{~min}$. The second stage included denaturation at $94^{\circ} \mathrm{C}$ for $35 \mathrm{~s}$, annealing at $51^{\circ} \mathrm{C}$ for $35 \mathrm{~s}$ and extension at $72^{\circ} \mathrm{C}$ for $35 \mathrm{~s}$, with totally 30 circulations. The third stage was extension at $72^{\circ} \mathrm{C}$ for $7 \mathrm{~min}$. The reaction system was $25 \mu \mathrm{L}$ in total, including $1 \mu \mathrm{L}$ cDNA, $1 \mu \mathrm{L}$ upstream primer and $1 \mu \mathrm{L}$ downstream primer of SUMO-1, $12.5 \mu \mathrm{L}$ Master Mix ( $2 \times$ Taq PCR), and the rest deionized water completed the $25 \mu \mathrm{L}$. The agarose gel electrophoresis (containing $5 \mu \mathrm{g} / \mathrm{mL}$ ethidium bromide) were conducted with $6 \mu \mathrm{L}$ PCR products, where observation and analysis were done. With target gene $=2^{-\Delta \Delta \mathrm{Ct}}$, the relative expression of 
Table 2. Upstream and downstream primer sequences of SUMO-1 and $\beta$-actin. Note: SUMO-1, small SUMO-1 ubiquitin-like modifier-1

\begin{tabular}{llr}
\hline Gene & \multicolumn{2}{c}{ Primer sequence } \\
\hline \multirow{2}{*}{ SUMO-1 } & Sense & 5'-AGGAGGCAAAACCTCAACT -3' \\
& Anti-sense & 5'-TTCTTCCTCCATTCCCAGTT-3' \\
\multirow{2}{*}{-actin } & Sense & 5'-ACACTGTGCCCATCTACGAGG -3 \\
& Anti-sense & 5'-AGGGGCCGGACTCGTCATACT-3' \\
\hline
\end{tabular}

target gene was calculated. $\Delta \Delta \mathrm{Ct}=$ (target gene $\mathrm{Ct}$ value of experimental group - reference gene Ct value of experimental group) - (target gene Ct value of control group - reference gene Ct value of control group). $\mathrm{Ct}$ value was the recurring number when fluorescence signal in each reaction tube reached the given field value. The quantitative primer in the experiments showed as Table 2.

\section{Western blotting}

SGC-7901 cells of each group were separately inoculated into five $10 \mathrm{~cm}$ cell culture plates by $1 \times 10^{6}$ cell/plate. They were cultured for $24 \mathrm{~h}$ at $37^{\circ} \mathrm{C} 5 \% \mathrm{CO}_{2}$ incubator. After that, Real-time Instant Presence with Advertisement (RIPA) lysis buffer was used to disintegrate them, where cell proteins extracted. After collecting supernatant by centrifugation, cell concentration of each group was measured by BCA Protein Assay Kit (Beyotime Biotechnology). Loading buffer added into proteins, they were boiled for 10 min at $95^{\circ} \mathrm{C}$. With $30 \mu \mathrm{g}$ loading amount in each well, proteins were isolated by $10 \%$ polyacrylamide gel electrophoresis, where the voltage of electrophoresis was $80 \mathrm{v}$ (spacer gel) to $120 \mathrm{v}$ (separation gel). After electrophoresis, membrane was transferred to Polyvinylidene Fluoride (PVDF) membrane in $60 \sim 90$ min by wet transfer method, where current was $250 \mathrm{~mA}$. Then they were closed for $2 \mathrm{~h}$ with $5 \%$ defatted milk at room temperature. The primary antibody SUMO-1 (ab32058, 1: 1000 attenuation), P53 (ab1101, 1: 1000 attenuation), bcl-2 (ab32124, 1: 1000 attenuation), and c-myc (ab32072, 1: 1000 attenuation) all bought from Abcam company (Boston United States), were added into specimens to shake overnight at $4{ }^{\circ} \mathrm{C}$. After that, they were washed by Phosphate Buffer Solution with Tween-20 (PBST) 3 times with 10 min per time. The next stage was incubating for $1 \mathrm{~h}$ on shaker at indoor temperature after adding matched secondantibody (1: 5000 attenuation), followed by which washed the membrane 3 times with 10 min per time. The results were observed by motored molecular imaging system. The protein expression of SUMO- 1 was represented by SUMO- $1 / \beta$-actin value.

\section{Statistical analysis}

All statistics were analyzed by SPSS 21.0 statistical software (SPSS, Chicago, IL, USA), and the data were expressed by mean value \pm standard deviation (mean \pm SD). Comparison between two groups was detected by $t$-test, while comparison among multiple groups was detected by one-way analysis of variance (One-Way ANOVA). Difference was considered as statistical significant if $P<0.05$.

\section{Results}

Comparison of SUMO-1 expression between GC tissues and adjacent normal tissues

SUMO-1 locates in cell nucleus and its expressions were widely distributed in various tissues and cells. Under optical microscope, positive expression was indicated by uneven thickness of dyed cell nucleus with color of yellowish to claybank. SUMO-1 expressions in GC tissues presented to be positive while the majority of that in adjacent normal tissues presented to be negative expression (Fig. 1). The color of poor-undifferentiated tumor showed to be deeper than well-moderate differentiated tumor.

\section{Morphological differences of GC primary cells and passage cells under light microscope}

The collagenase digestion extracted large quantity of GC cells, and caused low cell damage. After 60 minutes of collagenase digestion, cells were mostly single cell. The trypan blue staining detected rate of live cells by calculating stain-resistance rate, where live cells appeared to be transparent globule with stain-resistance rate over 91\%, while dead cells were blue (Fig. 2A). With short cell culture cycle, adherent cells reached $43 \%$ after $48 \mathrm{~h}$, and cellular morphology appeared to be fusiform and stoning to grow adhering to the wall. At the KARGER 


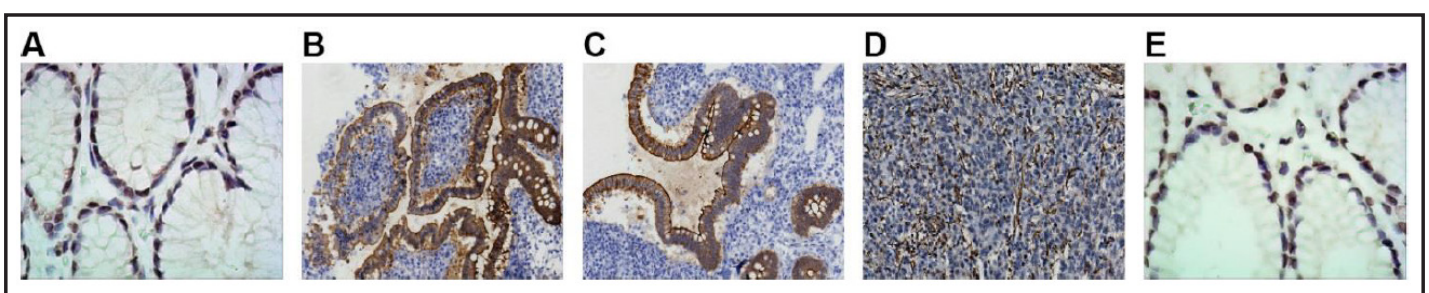

Fig. 1. SUMO-1 protein expression in different differentiated GC tissues and adjacent normal tissues $(x$ 400). Notes: GC, gastric cancer; A, adjacent normal tissue; B, gastric cancer tissue; C, well-moderate differentiated tumor; D, poor-undifferentiated tumor; E, negative control.

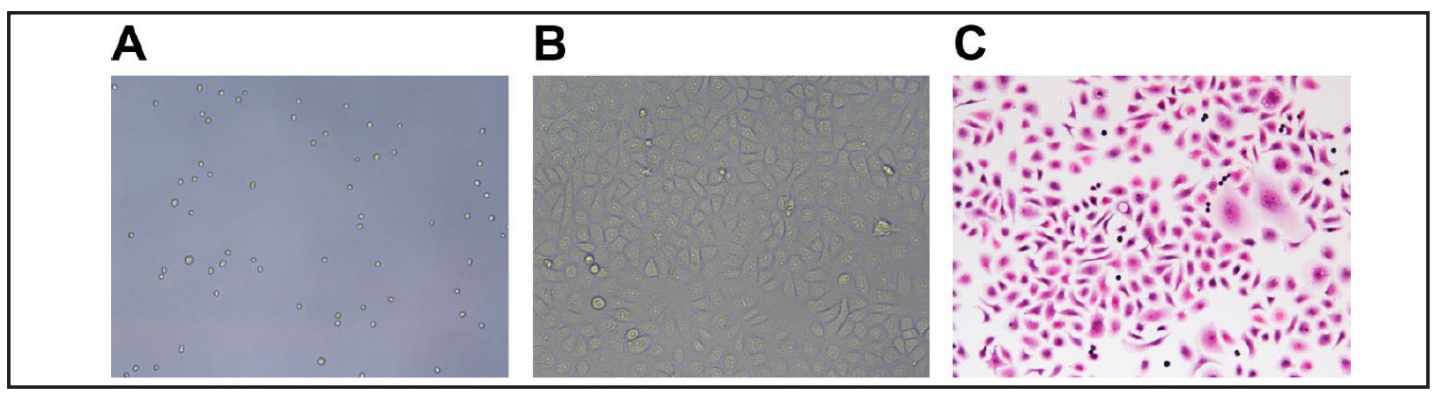

Fig. 2. Morphological differences of GC primary cells and passage cells extracted by collagenase digestion (200x). Notes: A, trypan blue staining of SGC-7901 cells; B, morphological changes of SGC-7901 cells under light microscopy; C, HE staining of SGC-7901 cells.

Fig. 3. The electrophoretogram of enzyme digestion analysis. Notes: M: Marker; 1: Empty vector; 2 : shRNA-SUMOI-1; 3: shRNA-SUMO-1-2; 4: shRNA-SUMO $1-3$.

$>$

third day, cells proliferated rapidly. One week later, primary cells grew to over $74 \%$ (Fig. 2B). Observed under light microscopic, major cellular morphology appeared to be fusiform and oval, a few appeared to be polygonal with tapering at two ends and clear nucleus, even some of them were polynuclear with clear nucleolus, which indicated to be big and deep color by HE staining, complying with features of SGC-7901 cells (Fig. 2C).

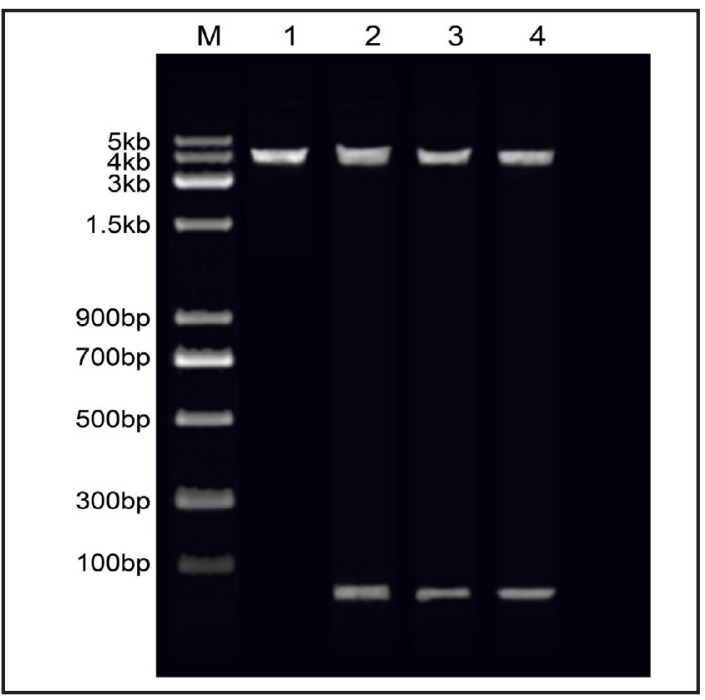

Enzymic digestion analysis and sequence analysis of recombinant plasmids

The study built three recombinant plasmids including shRNA-SUMOl-1, shRNA-SUMOl-2 and shRNA-SUMOl-3. They were double-enzyme digested by BamH 1 and Hind III, where 66 bp insert fragment and $4.2 \mathrm{~kb}$ linear plasmid pSilencerTM 3.1-H1 neo. The empty vector group was only transfected with empty vector plasmid. The results of recombinant plasmids identified by enzyme digestion analysis were correct as Figure 3.

Effect of shRNA transfection on SUMO gene silencing in the shRNA-SUMO-1-1, shRNASUMO-1-2 and ShRNA-SUMO-1-3 groups

The target sequences of SUMO-1 mRNA were separately encoded to shRNA-SUMO-1-1, ShRNA-SUMO-1-2 and shRNA-SUMO-1-3. Agarose gel electrophoresis results indicated shRNA-SUMO-1-1 group without SUMO-1 band while shRNA-SUMO-1-2 group and ShRNASUMO-1-3 group with visible SUMO-1 band, which suggested the latter two had poor gene 
Fig. 4. Effects of shRNA transfection on SUMO-1 gene silencing. Notes: A, the electrophoretogram of SUMO-1 mRNA expressions in each group; B, the cartogram of SUMO1 mRNA expressions in each group; $\mathrm{C}$, the electrophoretogram of SUMO1 mRNA expressions at different time in the shRNA-SUMO-1-1 group; D, the changing trend diagram of SUMO-1 mRNA expressions at different time in the shRNA-SUMO-1-1 group; E, the Western blotting image of SUMO-1 protein expressions at different time in the shRNA-SUMO-1-1 group; ** represented $P<0.01$ compared with the blank group; * represented $P<$ 0.05 compared with the blank group.
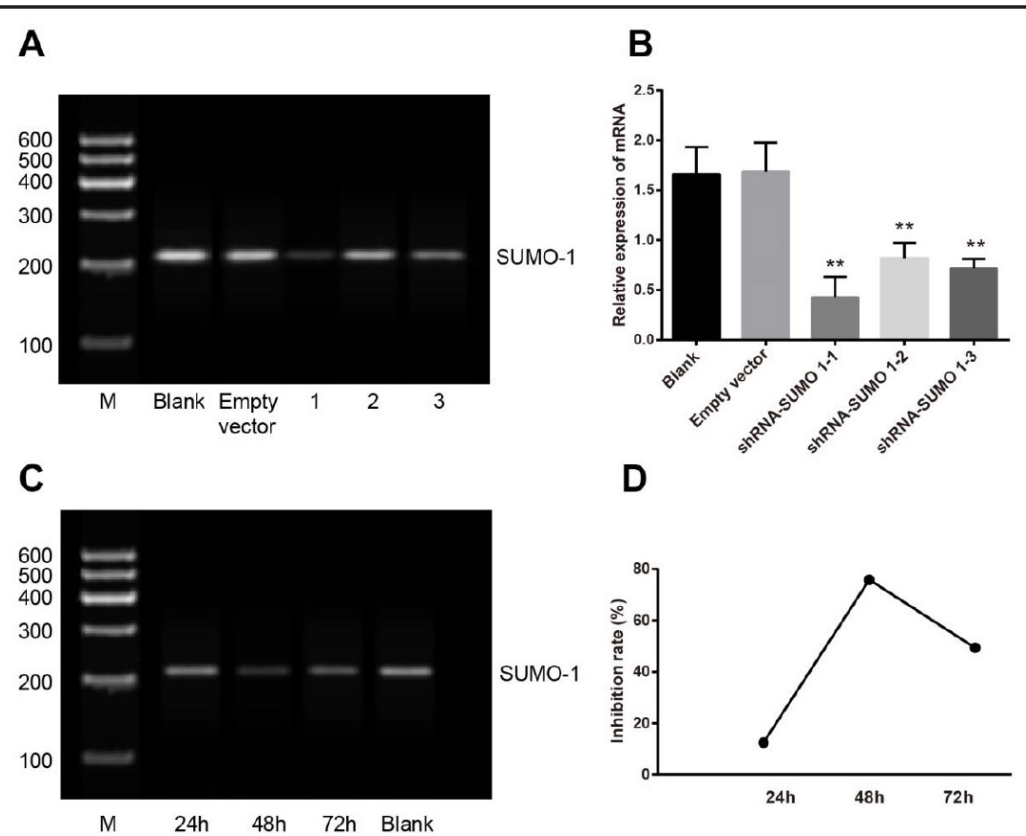

E

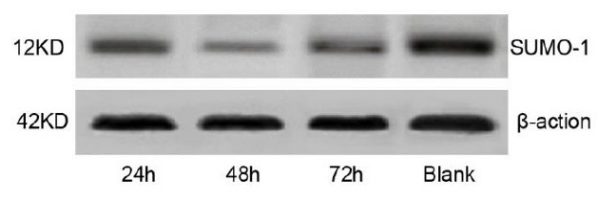

Fig. 5. Comparison of SGC-7901 cell proliferation in each group. Notes: CCK-8, cell counting kit-8; * represented $P<0.05$ when compared with the blank group.

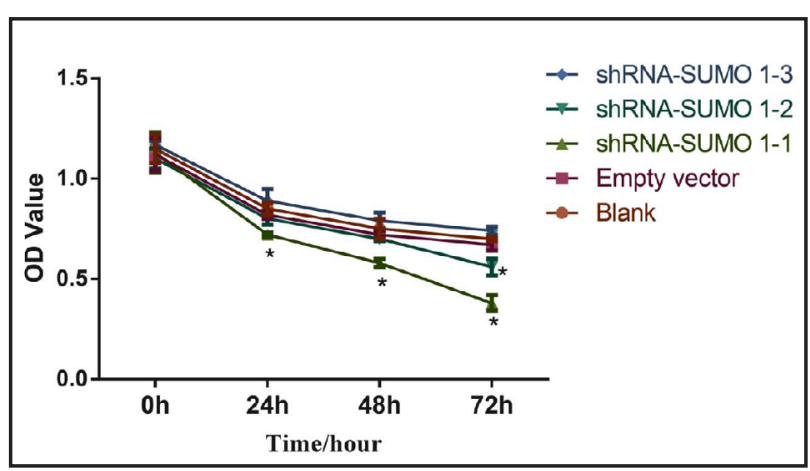

silence effect. There was no significant influence on SUMO-1 gene expression in the empty vector group (Fig. 4A). qRT-PCR results indicated SUMO-1 mRNA levels were significantly up-regulated in the shRNA-SUMO-1-1, shRNA-SUMO-1-2 and shRNA-SUMO-1-3 groups (all $P<0.05$ ), which were significantly different from both the blank group and the empty vector group (both $P<0.05$ ), as Figure 4B. By Image J software analysis of gray value, silence efficiency of shRNA-SUMO-1-1 at $24 \mathrm{~h}, 48 \mathrm{~h}$, and $72 \mathrm{~h}$ were respectively $12.47 \%, 75.84 \%$ and $49.36 \%$ (Fig. 4C D). By Western blot, the change of SUMO-1 expression was consistent with the change rule of qRT-PCR (Fig. 4E). All these results indicated that shRNA-SUMO-1-1 had the best silence effect on SUMO-1 than other two recombinant plasmids, where the best silence time was $48 \mathrm{~h}$.

Comparison of SGC-7901 cell proliferation in each group

CCk-8 method was applied to detect SGC-7901 cell proliferation after SUMO-1 interfered by shRNA. It's indicated that cell proliferation ability was significantly reduced by $24 \mathrm{~h}, 48 \mathrm{~h}$ and $72 \mathrm{~h}$ interference in the shRNA-SUMO-1-1 group when compared with the blank group

\section{KARGER}


Table 3. The proportions of specific cell cycle in each group by flow cytometry detection (n $=3, \%$, mean \pm standard devi-

\begin{tabular}{lccc}
\hline Groups & G0/G1 & S & G2/M \\
\hline Blank & $47.22 \pm 1.59$ & $20.00 \pm 1.49$ & $32.78 \pm 2.22$ \\
Empty vector & $48.35 \pm 1.31$ & $19.22 \pm 1.35$ & $32.43 \pm 2.62$ \\
shRNA-SUMO-1-1 & $56.70 \pm 2.36^{*}$ & $3.37 \pm 1.00^{*}$ & $39.92 \pm 1.95^{*}$ \\
shRNA-SUMO-1-2 & $47.04 \pm 1.29$ & $20.19 \pm 1.24$ & $32.77 \pm 1.10$ \\
shRNA-SUMO-1-3 & $48.46 \pm 1.28$ & $19.32 \pm 2.24$ & $32.22 \pm 2.35$ \\
\hline
\end{tabular}
ation). Note: * represented $P<$ shRNA-SUMO-1-2 0.05 when compared with the blank group

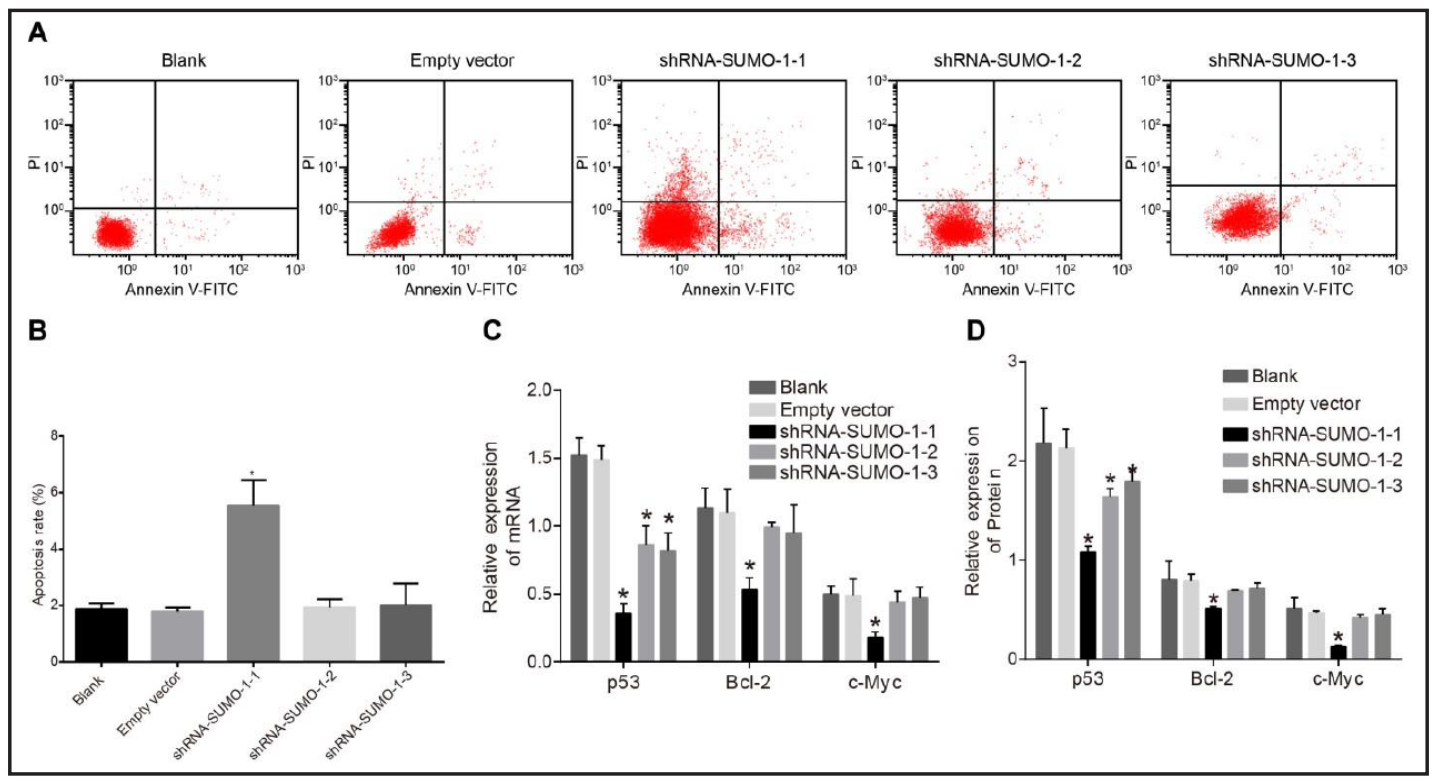

Fig. 6. Comparison of SGC-7901 cell apoptosis in each group. Notes: A, cell apoptosis detection by Annexin V/PI double staining and flow cytometry; B, statistical results of cell apoptosis in each group; C: expressions of bcl-2, c-myc and P53 mRNA in each group detected by agarose gel electrophoresis; D, expressions of bcl-2, c-myc and P53 protein detected by Western blotting; ${ }^{*}$ represented $P<0.05$ when compared with the blank group.

(all $P<0.05$ ). With the culture time increased, the inhibition of cell proliferation by shRNASUMO-1-1 showed a time-dependent effect. Compared with the blank group, after $24 \mathrm{~h}$ and $48 \mathrm{~h}$ interference in the shRNA-SUMO-1-2 group, cell proliferation was not reduced much, but after $72 \mathrm{~h}$ interference it was reduced significantly $(P<0.05)$. However, in the shRNASUM0-1-3 group, these three time points showed no obvious reduction of cell proliferation. And cell proliferation had no great changes in the empty vector group in comparison with the blank group (both $P>0.05$ ) (Fig. 5).

\section{Comparison of cell cycle of SGC-7901 cells in each group}

The cell cycle detection showed that cells transfection at G0/G1 stage in the shRNASUMO-1-1 group took up $56.70 \pm 2.36$ proportion of the whole cell cycle, which were significantly higher than that in the blank group $(G 0 / G 1=47.22 \pm 1.59)$ and that in the empty vector group $(48.35 \pm 1.31)$ (both $P<0.05)$. The proportion of $S$ stage cells in the blank group was $20.00 \pm 1.49$ while that in the shRNA-SUMO-1-1 group was $3.37 \pm 1.00$, much lower than that in the blank group $(P<0.05)$. The proportion of $\mathrm{G} 2 / \mathrm{M}$ stage cells in the shRNA-SUMO-1-1 group was 39.92 \pm 1.95 , which was much higher than that in the blank group (G2/M $=32.78 \pm 2.22)(P<0.05)$. Compared with the blank group, the proportions of G0/G1, S and G2/M stage in the empty vector group, the shRNA-SUMO-1-2 group and the shRNA-SUMO-1-3 group had no much changes (all $P>0.05$ ). The proportions of specific cell cycle in each group were showed as Table 3. 
Comparison of SGC-7901 cell apoptosis in each group

Cell apoptosis was detected by Annexin V/PI double staining and flow cytometry. After $48 \mathrm{~h}$ of transfection, cell apoptosis rate of the blank group was $1.87 \pm 0.22$, while the proportion of cell apoptosis in the shRNA-SUMO-1-1 group was $5.56 \pm 0.88$, which showed an increase of apoptosis rate in comparison with the blank group $(P<0.05)$. But the cell apoptosis rate of the shRNA-SUMO-1-2 group (1.92 \pm 0.30$)$ and that of the shRNA-SUMO-1-3 group $(2.02 \pm 0.77)$ were not significantly changed $(P>0.05)$. The cell apoptosis rate of the empty vector group was $1.80 \pm 0.12$, which is not different with that in the blank group $(P>$ 0.05 ) (Fig. 6A B). The apoptosis relevant mRNA expressions before and after transfection were detected by PCR method. The mRNA expressions of bcl-2 and c-myc in the shRNASUM0-1-1 group were declined significantly in comparison with blank group $(P<0.05)$. The plasmids shRNA-SUMO-1-1, shRNA-SUMO-1-2 and shRNA-SUMO-1-3 all had an inhibitory effect on the mRNA expressions of P53 (all $P<0.05$ ), among which shRNA-SUM0-1-1 had the greatest inhibitory effect, and this indicated shRNA-SUMO-1-1 can inhibit P53 endogenous expression of SGC-7901 cells (Fig. 6C). The apoptosis relevant expressions before and after transfection were detected by Western blot. Compared with the blank group, expression levels of bcl-2, c-myc and P53 proteins in the shRNA-SUMO-1-1 group were much reduced (all $P<0.05$ ), while expression levels of bcl-2 and c-myc in the shRNA-SUMO-1-2 group and the shRNA-SUMO-1-3 group were changed no so much (all $P>0.05$ ), and P53 in these two groups were decreased $(P<0.05)$. However, these three protein expressions in the empty vector group had no obvious change by comparison with the blank group (all $P>0.05$ ) (Fig. 6D).

\section{Discussion}

GC is one of the leading causes of cancer mortality worldwide and its management has evolved relatively little especially in advanced stages [16]. In recent years, significant progress has been made in the survival rate of GC patients, however, to reach a successful management of GC patients, biomarkers with high sensitivity and specificity in the prediction of the disease severity of GC are still in urgent needs [17]. It is reported that some genes are expressed in human malignancies abnormally, making their biological importance more apparent than before [18]. Hence, a better understanding of the molecular events of GC can lead to new preventive, diagnostic and therapeutic strategies to the disease [19].

In the present study, higher expression of SUMO-1 protein was found in GC tissues than in adjacent normal tissues. SUMO-1, a small protein significant for various biological processes, is conjugated to many intracellular proteins covalently, particularly to regulatory components of the transcriptional machinery, such as transcription and histones factors [20]. SUMO-1 is contained in SUMO family, and SUMO could maintain alternative lengthening of telomeres [21,22], and tumor cells always escape from the proliferation limitation that normal telomere shortening imposes by activating a telomere maintenance mechanism, either alternative lengthening of telomeres or telomerase [23]. Besides, SUMO was found to play a role in the signaling regulation of nuclear factor $-\kappa \mathrm{B}$, a tumor promoter in inflammationassociated cancer [24, 25]. Therefore, it can be concluded that SUMO plays an important role in the tumor development. In the present study, higher expression of SUMO-1 in GC tissues could further confirm the previous related studies. Similarly, over-expression of SUMO-1 appears in many mammalian cancer cells, such as squamous cell carcinoma of the lip, liver cancer and hepatocellular carcinoma [26-28].

Next, in the study, after transfection of shRNA-SUMO-1, GC SGC-7901 cells have decreased proliferation ability; in terms of cell cycle, proportion of cells at G0/G1phase increased while that of cells at G2/M phase decreased. SUMOylation is a vital post-translational modification characterized by reversibly and covalently binding SUMO proteins to target proteins [29]. Niu et al. also pointed out that SUMOylation plays an important regulatory role in various physiological process, including modulation of transcription, cell cycle and apoptosis

\section{KARGER}




\section{Cellular Physiology Cell Physiol Biochem 2017;41:987-998

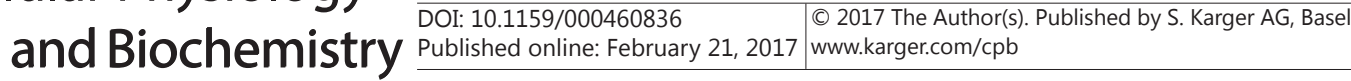 \\ Jin et al.: Effects of SUMO-1 Gene Silencing on Gastric Cancer}

[6]. Derksen et al. reported that stimulation of Wnt/ $\beta$-catenin signaling can increase cell proliferation, while blocking Wnt/ $\beta$-catenin signaling interferes with cancer cell growth [30]. Expression and activity of Wnt/ $\beta$-catenin target genes can be down-regulated after interference with SUMOylation through SUMO-1 silence, and SUMOylation inhibition can down-regulate $\beta$-catenin via promotion of ubiquitin-proteasomal mediated degradation at protein level [31]. Therefore, in the study, shRNA-SUMO-1 inhibits SUMOylation, blocks Wnt/ $\beta$-catenin signaling, and thus decreases cells proliferation. $\beta$-catenin may regulate the expression of CyclinD1 to promote cell invasion and proliferation [32], and Cyclin D1 is an important regulatory protein at the G1/S check point [33]. Therefore, with $\beta$-catenin downregulated by shRNA-SUMO-1, Cyclin D1 decreased, causing cells arrest at G0/G1 phase. Besides, it has been reported that apoptosis is closely associated with the G0/G1 arrest of cell cycle [34], therefore, higher apoptosis rate is observed in the study. To confirm the result, in Hao et al. study, inhibition of SUMO1 conjugation causes G1 arrest and abolishes the tumorigenic property and self-renewal of glioblastoma initiating of stem cells [35].

Finally, after transfection of shRNA-SUMO-1, expression level of Bcl-2, c-myc and p53 were declined. Bcl-2 family proteins, which have either anti- or pro-apoptotic activities, have always been studied for the past years owing to their significance in the regulation of tumorigenesis, apoptosis and cellular responses to anti-cancer therapy [34], and Bcl-2 is an anti-apoptotic protein [36]. A study has shown that $\beta$-Catenin up-regulate Bcl-2 [37], therefore in the study, shRNA-SUMO-1 inhibits $\beta$-catenin, further down-regulating Bcl-2. Besides, $\beta$-catenin can also regulate $c$-myc, whose transcription factor occurs frequently in human cancers and is related to tumor aggression and poor clinical prognosis [38]. Hence, in the same manner, shRNA-SUMO-1 inhibits $\beta$-catenin, further down-regulating c-myc. As for the correlation between SUM0-1and p53, many human tumors has been found to carry missense mutations in the TP53 gene [39], and cancer-associated p53 mutations also endow the mutant protein with new activities that can actively contribute to increased resistance to anticancer treatments and to various tumor progression stages [40]. Based on the result, it is believed that SUMO-1 gene promotes the expression of p53 mutations; therefore, with shRNA-SUMO-1, the p53 expression is down-regulated.

In summary, SUMO-1 gene silencing can decrease GCSGC-7901 cells proliferation, change cell cycle, promote cell apoptosis and down-regulate the expressions of Bcl-2, c-myc and P53 mutation, which provides a theoretical foundation for gene therapy against GC clinically.

\section{Acknowledgements}

This study was supported by the "Thirteenth Five-Year Plan" for Science and Technology Research Program of Education Department of Jilin Province (Ji Jiao Ke He Zi [2015] No.507). The authors appreciate the reviewers for their useful comments in this paper.

\section{Disclosure Statement}

The authors declare no conflicts of interest.

\section{References}

1 Sun W, Wang Q Chen B, Liu J, Liu H, Xu W: Gamma-tocotrienol-induced apoptosis in human gastric cancer SGC-7901 cells is associated with a suppression in mitogen-activated protein kinase signalling. Br J Nutr 2008;99:1247-1254.

- Hartgrink HH, Jansen EP, van Grieken NC, van de Velde CJ: Gastric cancer. Lancet 2009;374:477-490. Ai XH, Zheng X, Tang XQ Sun L, Zhang YQ Qin Y, Liu HQ Xia H, Cao JG: Induction of apoptosis of human gastric carcinoma SGC-7901 cell line by 5, 7-dihydroxy-8-nitrochrysin in vitro. World J Gastroenterol 2007;13:3824-3828. 


\section{Cellular Physiology Cell Physiol Biochem 2017;41:987-998

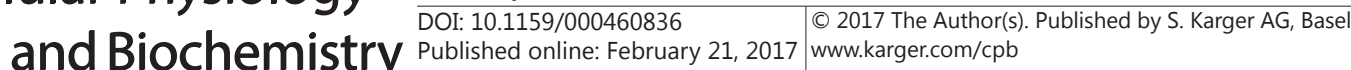 \\ Jin et al.: Effects of SUMO-1 Gene Silencing on Gastric Cancer}

4 Catalano V, Labianca R, Beretta GD, Gatta G, de Braud F, Van Cutsem E: Gastric cancer. Crit Rev Oncol Hematol 2005;54:209-241.

5 Sakuramoto S, Sasako M, Yamaguchi T, Kinoshita T, Fujii M, Nashimoto A, Furukawa H, Nakajima T, Ohashi Y, Imamura H, Higashino M, Yamamura Y, Kurita A, Arai K, Group A-G: Adjuvant chemotherapy for gastric cancer with S-1, an oral fluoropyrimidine. N Engl J Med 2007;357:1810-1820.

6 Niu L, Qin HZ, Xi HQ Wei B, Xia SY, Chen L: RNF43 Inhibits Cancer Cell Proliferation and Could be a Potential Prognostic Factor for Human Gastric Carcinoma. Cell Physiol Biochem 2015;36:1835-1846.

7 Chen X, Deng C, Tang S, Zhang M: Mitochondria-dependent apoptosis induced by nanoscale hydroxyapatite in human gastric cancer SGC-7901 cells. Biol Pharm Bull 2007;30:128-132.

-8 Wu K, Li Y, Zhao Y, Shan YJ, Xia W, Yu WP, Zhao L: Roles of Fas signaling pathway in vitamin E succinateinduced apoptosis in human gastric cancer SGC-7901 cells. World J Gastroenterol 2002;8:982-986.

$>9$ Jia L, Huang XL, Zhao Y, Zhang XG, Wu K: Vitamin E succinate (VES) inhibits cell growth and induces apoptosis by mitochondrial-derived ROS in SGC-7901 cells. Med Sci Monit 2010;16:BR131-139.

10 Mukherjee S, Thomas M, Dadgar N, Lieberman AP, Iniguez-Lluhi JA: Small ubiquitin-like modifier (SUMO) modification of the androgen receptor attenuates polyglutamine-mediated aggregation. J Biol Chem 2009;284:21296-21306.

11 Rosas-Acosta G, Russell WK, Deyrieux A, Russell DH, Wilson VG: A universal strategy for proteomic studies of SUMO and other ubiquitin-like modifiers. Mol Cell Proteomics 2005;4:56-72.

12 Yang W, Wang L, Roehn G, Pearlstein RD, Ali-Osman F, Pan H, Goldbrunner R, Krantz M, Harms C, Paschen W: Small ubiquitin-like modifier 1-3 conjugation [corrected] is activated in human astrocytic brain tumors and is required for glioblastoma cell survival. Cancer Sci 2013;104:70-77.

$\checkmark 13$ Rohira AD, Chen CY, Allen JR, Johnson DL: Covalent small ubiquitin-like modifier (SUMO) modification of Maf1 protein controls RNA polymerase III-dependent transcription repression. J Biol Chem 2013;288:19288-19295.

14 Bawa-Khalfe T, Yeh ET: SUMO Losing Balance: SUMO Proteases Disrupt SUMO Homeostasis to Facilitate Cancer Development and Progression. Genes Cancer 2010;1:748-752.

15 Yang W, Paschen W: Gene expression and cell growth are modified by silencing SUMO2 and SUMO3 expression. Biochem Biophys Res Commun 2009;382:215-218.

16 Gravalos C, Jimeno A: HER2 in gastric cancer: a new prognostic factor and a novel therapeutic target. Ann Oncol 2008;19:1523-1529.

17 Liu Y, Xu J, Jiang M, Ni L, Chen Y, Ling Y: Association between functional PSMD10 Rs111638916 variant regulated by MiR-505 and gastric cancer risk in a Chinese population. Cell Physiol Biochem 2015;37:10101017.

18 Xia L, Zhang D, Du R, Pan Y, Zhao L, Sun S, Hong L, Liu J, Fan D: miR-15b and miR-16 modulate multidrug resistance by targeting BCL2 in human gastric cancer cells. Int J Cancer 2008;123:372-379.

19 Qu Y, Dang S, Hou P: Gene methylation in gastric cancer. Clin Chim Acta 2013;424:53-65.

-20 Weger S, Hammer E, Heilbronn R: Topors acts as a SUMO-1 E3 ligase for p53 in vitro and in vivo. FEBS Lett 2005;579:5007-5012.

-21 Gong L, Yeh ET: Characterization of a family of nucleolar SUMO-specific proteases with preference for SUMO-2 or SUMO-3. J Biol Chem 2006;281:15869-15877.

22 Nagai S, Davoodi N, Gasser SM: Nuclear organization in genome stability: SUMO connections. Cell Res 2011;21:474-485.

-23 Jiang WQ Zhong ZH, Henson JD, Neumann AA, Chang AC, Reddel RR: Suppression of alternative lengthening of telomeres by Sp100-mediated sequestration of the MRE11/RAD50/NBS1 complex. Mol Cell Biol 2005;25:2708-2721.

24 Mabb AM, Miyamoto S: SUMO and NF-kappaB ties. Cell Mol Life Sci 2007;64:1979-1996.

25 Karin M: Nuclear factor-kappaB in cancer development and progression. Nature 2006;441:431-436.

26 Oliveira Alves MG, da Mota Delgado A, Balducci I, Carvalho YR, Cavalcante AS, Almeida JD: Study of MDM2 and SUMO-1 expression in actinic cheilitis and lip cancer. Arch Dermatol Res 2014;306:837-841.

27 Ma KW, Au SW, Waye MM: Over-expression of SUMO-1 induces the up-regulation of heterogeneous nuclear ribonucleoprotein A2/B1 isoform B1 (hnRNP A2/B1 isoform B1) and uracil DNA glycosylase (UDG) in hepG2 cells. Cell Biochem Funct 2009;27:228-237.

-28 Guo WH, Yuan LH, Xiao ZH, Liu D, Zhang JX: Overexpression of SUMO-1 in hepatocellular carcinoma: a latent target for diagnosis and therapy of hepatoma. J Cancer Res Clin Oncol 2011;137:533-541. 


\section{Cellular Physiology Cell Physiol Biochem 2017;41:987-998

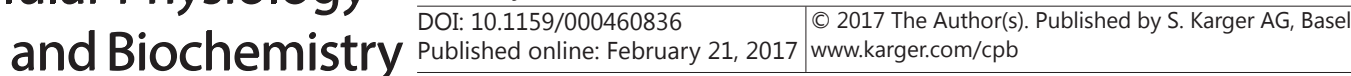 \\ Jin et al.: Effects of SUMO-1 Gene Silencing on Gastric Cancer}

29 Geiss-Friedlander R, Melchior F: Concepts in sumoylation: a decade on. Nat Rev Mol Cell Biol 2007;8:947956.

-30 Derksen PW, Tjin E, Meijer HP, Klok MD, MacGillavry HD, van Oers MH, Lokhorst HM, Bloem AC, Clevers H, Nusse R, van der Neut R, Spaargaren M, Pals ST: Illegitimate WNT signaling promotes proliferation of multiple myeloma cells. Proc Natl Acad Sci U S A 2004;101:6122-6127.

-31 Dai Y, Han K, Zou Z, Yan S, Wang Y, Zhang Z: SUMO-1 of mud crab (Scylla paramamosain) in gametogenesis. Gene 2012;503:260-268.

-32 Zhao C, Zhang M, Liu W, Wang C, Zhang Q Li W: beta-Catenin knockdown inhibits pituitary adenoma cell proliferation and invasion via interfering with AKT and gelatinases expression. Int J Oncol 2015;46:16431650.

33 Catarino R, Pereira D, Breda E, Coelho A, Matos A, Lopes C, Medeiros R: Oncogenic virus-associated neoplasia: a role for cyclin D1 genotypes influencing the age of onset of disease? Biochem Biophys Res Commun 2008;370:118-122.

34 Youle RJ, Strasser A: The BCL-2 protein family: opposing activities that mediate cell death. Nat Rev Mol Cell Biol 2008;9:47-59.

35 Hao C, Bellail A: 2. SUM01-CDK6 conjugation drives the cell cycle and retains the self renewal of glioblastoma stem cells. Can J Neurol Sci 2015;42:S2-S2.

-36 Fuenzalida K, Quintanilla R, Ramos P, Piderit D, Fuentealba RA, Martinez G, Inestrosa NC, Bronfman M: Peroxisome proliferator-activated receptor gamma up-regulates the Bcl-2 anti-apoptotic protein in neurons and induces mitochondrial stabilization and protection against oxidative stress and apoptosis. J Biol Chem 2007;282:37006-37015.

37 Li L, Chapman K, Hu X, Wong A, Pasdar M: Modulation of the oncogenic potential of beta-catenin by the subcellular distribution of plakoglobin. Mol Carcinog 2007;46:824-838.

-38 Huang HJ, Zhou LL, Fu WJ, Zhang CY, Jiang H, Du J, Hou J: beta-catenin SUMOylation is involved in the dysregulated proliferation of myeloma cells. Am J Cancer Res 2015;5:309-320.

39 Xu DH, Tang J, Li QF, Shi SL, Chen XF, Liang Y: Positional and expressive alteration of prohibitin during the induced differentiation of human hepatocarcinoma SMMC-7721 cells. World J Gastroenterol 2008;14:5008-5014.

40 Oren M, Rotter V: Mutant p53 gain-of-function in cancer. Cold Spring Harb Perspect Biol 2010;2:a001107. 